\title{
The Patient Profile of a Uk Osteopathic Student Out-patient Clinic: a Retrospective Descriptive Study
}

Andrew MacMillan ( MacMillan.a@lso.ac.uk)

\section{Research}

Keywords: Osteopathy, audit, epidemiology, pain

Posted Date: June 11th, 2020

DOI: https://doi.org/10.21203/rs.3.rs-34316/v1

License: (c) (i) This work is licensed under a Creative Commons Attribution 4.0 International License. Read Full License 


\section{Abstract}

Osteopathy is a healthcare discipline regulated by statute within the UK. Little is known regarding the day-to-day practice of osteopaths. The aim of this study was to investigate the patient profile within a teaching institution. Data regarding patients and their presenting symptoms are routinely collected at UK OEls. The data were analysed from a sample spanning three years. The demographic data collected described the patient population sample in terms of age range, gender, occupation and ethnicity. The patient symptom data collected was comprised of site of pain, aetiology, symptom duration and symptom pattern. The study first profiles the clinic patient population, describing the prevalence of the types of presenting complaint, and then profiles the demographics of the sample. The study then compared the demographic data to the symptom data to assess for trends within the sample.

\section{Methods}

Data from a total of 3,760 patient records attending between $02 / 01 / 13$ and 24/12/15 were analysed. This data was cleansed leaving 3243 complete patient records. The data was then analysed using descriptive and inferential statistics via the StatisticalPackage for Social Sciences. The statistical tests used were the nonparametric test, Kendall's rank order correlation, and Pearson's Chi-Square correlations for the ordinal data. Distributions and frequency counts were performed to describe the data using Microsoft excel.

\section{Results}

The sample of the clinic population analysed included 3243 patient records, of which 1834 were female (57\%) and 1408 (43\%) were male. The ethnic profile of included records was predominantly Caucasian at $68 \%$, with $13 \%$ of Black Minority Ethnic origin and $12 \%$ South Asian. The age range is from 0 to $80+$ years, and the majority of participants are aged 30-39 (31\%). The most common sites of pain were: low back (33\%), neck (23\%), upper back (9\%), mid back (7\%), and shoulder (6\%). The results suggest that gender may influence site of pain, and that ethnicity is not associated with symptom duration but may be associated with symptom site and pattern, however the association is weak and may not be generalizable beyond this cohort. No statistical significance was found between occupation and pain.

\section{Conclusion}

This study is a detailed profile of a UK OEls clinic's patient population. It investigated potential links between demographic data and presenting complaints. Further study with a larger sample size would allow more reliable analysis of data, repeating similar investigation at other institutions may enhance understanding of this topic and highlight if regional differences occur. This study highlights that there are no discernable correlation between pain presentation and occupation or ethnicity.

\section{IMPLICATIONS FOR PRACTICE}

This study adds to the existing research literature by:

Profiles the patient population of a UK OEI with reference to; ethnicity, age and gender.

Demonstrates a relationship between gender and sites of pain and no link between occupation and presenting complaint.

\section{Introduction}

\section{Background}

Musculoskeletal (MSK) conditions are a major burden to the individual, society and the health service; $15-20 \%$ of all GP consultations are for MSK presentations at a substantial cost to the NHS and the wider UK economy accounting for $£ 4.76$ 
billion of National Health Service (NHS) spending each year in direct costs alone with an additional economic burden of approximately 10.8 million work days lost [1,2].

The estimated annual cost of low back pain alone is between $£ 5-7$ billion a year [3], with chronic low back pain being more of a financial burden than acute low back pain [4]. The lifetime prevalence of low back pain is reported to be as high as $84 \%$ of the general population and the prevalence of chronic low back pain is about $23 \%$, with $11-12 \%$ of the population being disabled by low back pain [5].

Osteopaths are allied health professionals specializing in MSK conditions [6,7]. Osteopaths treat a wide range of musculoskeletal conditions including but not limited to the spine $[6,8]$.

\section{Rationale}

Overall, the types of patients seeking osteopathic treatment and the conditions with which they generally present is unknown, as few previous research studies have been conducted to sufficiently address this question [9]. It is not currently known if any musculoskeletal complaint is more prevalent within osteopathic practice than another nor where osteopathy can be best utilised to have the greatest benefit to the UK healthcare system [10].

Carnes and Fawkes [10], highlight the importance to the profession of collecting data regarding clinical practice. Previously data has been collected from small surveys mostly in single private practice settings and within a single osteopathic educational institution $[11,12,13,14]$. These previous works are descriptive in nature and do not compare demographic and symptomology data. It is not known if patient demographics have changed since their publication, as the dates range from 1981-2014, these factors highlight a gap in the literature which this study aims to address.

\section{$\underline{\text { Objectives }}$}

To present demographic data regarding patient profiles and discuss any links between presenting complaints and patient demographics.

To highlight any groups with increased prevalence of a presenting complaint and identify any demographic risk factors for MSK pain.

\section{Methods}

\section{Study design}

This study is a retrospective descriptive study of the patient profile of a UK osteopathy teaching clinic. Ethical approval was gained from the university ethics panel prior to commencement and all data were anonymised prior to the researchers receiving it. This study profiles the clinic patient population discusses trends in patients' presenting symptoms and demographic factors. Site of pain, symptom duration and symptom pattern were analyzed with reference to age, gender and ethnicity to identify if symptom sets are more prevalent in any demographic group.

\section{Setting \& Participants}

Data from consenting patients in UK OEls is routinely collected by students. Data collected between 2013 and 2015 from consenting patients at a single institution was accessed and statistical analyses performed.

\section{Data sources/measurement}

Data was accessed from 3,760 consenting patients attending between 02/01/13 and 24/12/15. The data were anonymised by giving each patient a unique patient reference number, which was then replaced by sequential numbers 
after the data order had been randomised, the data was stored and accessed in Microsoft Excell.

Bias

This information was filtered to exclude incomplete entries and those containing errors, this resulted in 517 unusable entries being removed. Data is recorded by students based on patient reports this may be a source of error. The groups consisting of Black Caribbean, Black African, and Black Other did not individually have enough participants to attain statistical significance. Therefore, were combined into a Black Minority Ethnic group (BME). This was also true of the Indian, Bangladeshi and Pakistani groups, which were consequently amalgamated into a South Asian group. Only the three most prevalent sites of pain met the threshold for sample size calculations which limited analysis of data.

\section{$\underline{\text { Variables }}$}

Table 1 lists the data categories and their contents, which were used in this study.

Table 1

Categories and Contents within the Data

\begin{tabular}{|c|c|c|c|c|c|c|c|c|}
\hline Catagory & Gender & Ethnicity & Occupation & $\begin{array}{l}\text { Symptom } \\
\text { Duration }\end{array}$ & $\begin{array}{l}\text { Symptom } \\
\text { Pattern }\end{array}$ & $\begin{array}{l}\text { Symptom } \\
\text { Site }\end{array}$ & Aetiology & $\begin{array}{l}\text { Age } \\
\text { Range }\end{array}$ \\
\hline Option & Male & $\begin{array}{l}\text { White } \\
\text { (Caucasian) }\end{array}$ & Professional & $\begin{array}{l}\text { Acute / 0- } \\
3 \text { days }\end{array}$ & $\begin{array}{l}\text { One } \\
\text { episode / } \\
\text { One site }\end{array}$ & Head & Trauma & $0-12$ \\
\hline Option & Female & $\begin{array}{l}\text { Black } \\
\text { Caribbean }\end{array}$ & Clerical & $\begin{array}{l}\text { Semi } \\
\text { acute / } 4 \\
\text { days-3 } \\
\text { weeks }\end{array}$ & $\begin{array}{l}\text { Recurring } \\
\text { one site }\end{array}$ & Neck & Degenerative & $13-19$ \\
\hline Option & & $\begin{array}{l}\text { Black } \\
\text { African }\end{array}$ & Manual & $\begin{array}{l}\text { Sub } \\
\text { chronic / } \\
3 \text { weeks- } \\
3 \text { months }\end{array}$ & $\begin{array}{l}\text { One } \\
\text { episode } \\
\text { multiple } \\
\text { sites }\end{array}$ & $\begin{array}{l}\text { Upper } \\
\text { back }\end{array}$ & $\begin{array}{l}\text { Repetitive } \\
\text { (occupation) }\end{array}$ & $20-29$ \\
\hline Option & & Black Other & Unemployed & $\begin{array}{l}\text { Chronic / } \\
\text { more } \\
\text { than } 3 \\
\text { months }\end{array}$ & $\begin{array}{l}\text { Recurring } \\
\text { multiple } \\
\text { sites }\end{array}$ & Mid back & $\begin{array}{l}\text { Repetitive } \\
\text { (sport) }\end{array}$ & $30-39$ \\
\hline Option & & Indian & Student & & & Low back & Systemic & $40-49$ \\
\hline Option & & Pakistani & Retired & & & Pelvis & Psychological & $50-59$ \\
\hline Option & & Bangladeshi & $\begin{array}{l}\text { House } \\
\text { person }\end{array}$ & & & Coccyx & Other & $60-69$ \\
\hline Option & & Chinese & $\begin{array}{l}\text { Child under } \\
6\end{array}$ & & & Chest/ribs & & $70-79$ \\
\hline Option & & Other & Other & & & Abdomen & & $80+$ \\
\hline
\end{tabular}

\section{Statistical methods}

The statistical tests used were the nonparametric test, Kendall's rank order correlation, and Pearson's Chi-Square correlations for the ordinal data. Distributions and frequency counts were performed to describe the data.

\section{Results}


The sample of the clinic population included 1834 female (57\%) and 1408 (43\%) male data sets. The ethnic profile of the clinic is predominantly Caucasian (68\%) and age ranged from 0-80+ years with most participants aged 30-39 years (1003 or $31 \%)$. Lower back pain is the most prevalent presenting complaint.

The prevalence of each site of pain is detailed in Figure 1.

\section{Duration of pain}

The majority of patient presentations were chronic at $54 \%$ (1771), followed by semi-acute at $19 \%$ (644), sub-chronic at $19 \%$ (641), and acute at 6\% (186).

\section{Gender and pain}

Within the male sample, 496 had low back pain. This comprised $47 \%$ of the low back pain group and $35 \%$ of male subjects. Within the female sample, 554 had low back pain. This accounted for $53 \%$ of the low back pain group and $30 \%$ of the female sample.

Female patients present with neck pain more frequently than male patients, 291 men presented with neck pain. This made up $40 \%$ of the neck pain population and $20 \%$ of the total male population. Women account for $60 \%$ of the neck pain group, which is $24 \%$ (447) of the female population. The other pain sites were broadly similar by gender.

The Yule's $Q$ test was performed, $Q=0.69$ indicated a moderate relationship between gender and site of pain, $P<0.005$.

\section{Ethnic Differences}

The ethnic profile of the study population is detailed in table 2.

Table 2

The Ethnic Distribution of the Sample Population

\begin{tabular}{|llll|}
\hline Ethic Grouping & Specific Ethnicity & Number of patients & Percentage \\
\hline White & White (Caucasian) & 2203 & $68 \%$ \\
\hline BME & Black Caribbean & 217 & $7 \%$ \\
\hline & Black African & 122 & $4 \%$ \\
\hline South Asian & Black Other & 67 & $2 \%$ \\
\hline & Indian & 188 & $6 \%$ \\
\hline & Pakistani & 91 & $3 \%$ \\
\hline Chinese & Bangladeshi & 106 & $3 \%$ \\
\hline Other & Chinese & 81 & $1 \%$ \\
\hline & Other Ethnic Group & 217 & $6 \%$ \\
\hline
\end{tabular}

The most common sites of pain by ethnic group are shown in table 3, low back pain was most prevalent in all but the Chinese group, followed by neck pain. The BME group has a higher percentage of low back pain than the other groups. 
Table 3

Pain Site by Ethnicity

\begin{tabular}{|llll|}
\hline Ethnicity & Neck pain & Low back pain & Upper back pain \\
\hline Caucasian & $23 \%(506)$ & $29 \%(638)$ & $10 \%(220)$ \\
\hline Black Minority Ethnic & $16 \%(63)$ & $41 \%(162)$ & $5 \%(19)$ \\
\hline South Asian & $23 \%(8)$ & $38 \%(146)$ & $7 \%(26)$ \\
\hline Chinese & $12 \%(9)$ & $10 \%(8)$ & $19 \%(15)$ \\
\hline Other & $20 \%(43)$ & $34 \%(73)$ & $7 \%(15)$ \\
\hline
\end{tabular}

Yule's $Q$ test showed a value of $Q=0.26$, thus indicating a weak association between ethnicity and symptom site, with a standard error of 0.23 and not achieving statistical significance, $p=0.260$.

Ethnicity and Symptom Duration

There was no discernible pattern to ethnicity and symptom duration.

\section{Occupation}

The occupation category consisted of professional, at 49\% (1617), clerical, at 9\% (302), manual, at 12\% (394), unemployed, at $4 \%$ (156), student, at $6 \%(204)$, and retired, at $9 \%$ (306). The other $11 \%$ of patients consisted of house person, at $2 \%(87)$, child, at $2 \%(79)$, and other, at $9 \%$ (299). For this analysis entries with multiple categories were allocated to the 'other' category. No statistical significance was found between occupation and pain.

\section{Difference in Pain Presentation by Age Group}

There is a wide age range in the patient sample, as can be seen in the table 4, which shows the prevalence of each age range:

Table 4

Distribution of age

\begin{tabular}{|lll|}
\hline Age Group & Number & Percentage of the Patient Population \\
\hline $0-12$ & 84 & $3 \%$ \\
\hline $13-19$ & 66 & $2 \%$ \\
\hline $20-29$ & 722 & $22 \%$ \\
\hline $30-39$ & 1003 & $31 \%$ \\
\hline $40-49$ & 544 & $16.8 \%$ \\
\hline $50-59$ & 397 & $12 \%$ \\
\hline $60-69$ & 242 & $7 \%$ \\
\hline $70-79$ & 144 & $4 \%$ \\
\hline $80+$ & 32 & $1 \%$ \\
\hline
\end{tabular}


Lower back pain is the most common site by all ages, except for 0-12 this may be due to the common treatment of young children with cranial techniques leading to listing of Head pain. The distribution by age is uniform across all ages.Table 5 show the relationship between site of pain and age.

Table 5

Site of Pain by Age Group

\begin{tabular}{|lllll|}
\hline Age range & Head pain & Neck pain & Low back pain & Upper back pain \\
\hline $0-12$ & $44 \%$ & $16 \%$ & $7 \%$ & $4 \%$ \\
\hline $13-19$ & $6 \%$ & $19 \%$ & $24 \%$ & $10 \%$ \\
\hline $20-29$ & $5 \%$ & $22 \%$ & $27 \%$ & $14 \%$ \\
\hline $30-39$ & $4 \%$ & $23 \%$ & $33 \%$ & $9 \%$ \\
\hline $40-49$ & $5 \%$ & $24 \%$ & $33 \%$ & $8 \%$ \\
\hline $50-59$ & $3 \%$ & $23 \%$ & $37 \%$ & $6 \%$ \\
\hline $60-69$ & $1 \%$ & $20 \%$ & $35 \%$ & $6 \%$ \\
\hline $70-79$ & $3 \%$ & $16 \%$ & $41 \%$ & $4 \%$ \\
\hline $80+$ & $3 \%$ & $21 \%$ & $37 \%$ & $9 \%$ \\
\hline
\end{tabular}

Kendall's rank order correlation was performed and showed a strong association between age and symptom site with a value of 0.87 . The standard error was 0.14 , approximate Tb was 6.026 and $P$ value $<0.01$.

\section{Aetiologie}

The most common aetiologiesof pain onset by category were: repetitive (occupation) at $35 \%$, trauma at $21 \%$, degenerative change at $19 \%$, repetitive (sports) at $15 \%$. Repetitive (occupation) is significantly higher in the age range 20-59 years. However, above 59 years old it is degenerative change that is the most prevalent aetiology. Repetitive (sport) decreases as a prevalent aetiology above the age of 60 . However, these patterns are not statistically significant.

The relationships between; age and duration of symptoms and age and aeteology were not statistically significant.

\section{Age and Symptom Pattern}

The data show the category 'multiple episodes one site' to be the most prevalent in 20-39 year olds, and multiple sites, multiple episodes to be the most prevalent in those aged over 70 . The remaining categories did not vary by age.

The data appears to show that symptom pattern is affected by increasing age. The, Kendall's rank order coefficient $=0.45$ showing a moderate association $\mathrm{P}>0.002$.

\section{Discussion}

This study included all available data from participants who had provided consent for anonymous data to be used in research. This study was as representative as possible of the clinic population being sampled to produce more reliable results $[15,16]$. However, when data were analyzedthe data failed to meet appropriatley powered sample sizes. It is hoped 
that these results will contribute to what is already known about the practice of osteopathy, and will highlight any changes since previous studies, although this study may only be relevant to the institution in which it occurred.

\section{Gender Differences}

Slightly more females (57\%) seek osteopathic treatment than males.

The reporting of lumbar spine complaints in this study was lower overall than in other studies, at $33 \%$ compared to $36 \%$ in Fawkes et al [10]. In this study male subjects appear to be $5 \%$ more likely to suffer with low back pain. Bailey et al [17], highlights sexual dimorphic differences in the lumbopelvic region, biopsychosocial factors and differences in lifestyle as contributing factors to this gender disparity. It is inherently uncertain if differences are due to structural variation or other confounding variables. This study raises questions, such as whether pain is more prevalent in females or whether men make different choices regarding treatment.

\section{Differences by}

The distribution of ages in this study was similar to that of other [10], with most patients being of working age between 2059 with the majority aged 30-39. It has been postulated that cost is a barrier to accessing CAM for some groups, including the elderly [18]. However, the cost of treatment at training establishments is considerably less than within the registered profession [19]. This may help to mitigate the impact of cost as a barrier to treatment. However, those aged over 60, who are more likely to be retired and who would thus arguably benefit from the lower fees, only accounted for $12 \%$ of the patient population. This suggests that other barriers may exist among the older population, and it is an area that would benefit from further study, so that strategies to improve universal access to osteopathic care can be developed.

The paediatric group (3\%) is similar to that seen in the wider profession (4\%), as detailed by Wilkinson et al [20]. Furthermore, a greater prevalence of complaints of the head and face in the paediatric sample compared with the adult sample was also found within this study, at $44 \%$.

The data show degenerative change as an aetiology is more prevalent in patients above the age of 50 . The reasoning behind this is less clear than it would seem. Though osteoarthritis (OA) is more commonly found in imaging of older adults [21], Anderson and Loeser [22], highlight that joint pain in older adults is not always due to OA, even when radiographs show OA changes, since these changes are common in older adults. Furthermore, findings of OA on plain radiographs do not correlate well with symptoms. These findings therefore raise the question of whether a diagnosis of degenerative change is truly accurate in explaining older patients' symptoms, or whether it is merely a reflection of the practitioner's bias.

When looking at low back pain, it appears that the percentage of the population suffering from this complaint is not affected by age. Although there is an increase in the 70-79 age range (which then decreases over the age of 80), this could be due to the small sample size.

The study's findings suggest that older patients have more chronic pain and greater instances of recurrent and multiple sites of pain than younger patients. Paladini et al [23], suggest central sensitisation is more prevalent in the elderly and postulate possible mechanisms for this, which would suggest that pain threshold actually increases with age. However, as Neogi [24], notes central inhibitory mechanisms decrease resulting in more pain.

McBeth, Lacey and Wilkie [25], suggest that one in four patients aged over 65 years present to their GP for evaluation of musculoskeletal pain. It is estimated that between $46 \%$ and $80 \%$ of individuals aged over 65 experience musculoskeletal pain daily. The authors look at multiple contributing factors including depression and social isolation.

Differences by Ethnicity. 
No statistically significant results were found in the relationship between pain pattern and ethnicity. However, certain trends were identified. Chinese patients seem to have fewer incidences of recurrent multiple site pain and more single site recurrent pain. Furthermore, South Asians had a slight increase in multiple site multiple episode pain and a corresponding decrease in the single pain site categories. Caucasian and BME patients displayed similar results. Although incidences of neck pain were broadly similar across all ethnic groups, low back pain was most prevalent among the BME group at $41 \%$, closely followed by the South Asian group, at $38 \%$. The differences in distribution by ethnic group of other pain sites were negligible and no statistical significance was found to exist. No previous osteopathic studies have compared these groups. These results may therefore corroborate the findings of Smith et al (2016), which show broadly similar rates of musculoskeletal pathology amongst different ethnic groups in the UK and America.

The findings from the 'other' population are not dissimilar to the South Asian and Caucasian population. It is worth noting that the Chinese group was the smallest ethnic group and so the results may not accurately reflect a larger population sample [15].

\section{Differences by Occupation}

No links were found between type of occupation and presenting complaint in this study. Farioli et al [26], also found no link between occupation and musculoskeletal pain but did find a link between pain presentation and socioeconomic factors. Their study included 40,000 participants across twenty-seven European countries, and interestingly showed that there was a higher pain prevalence in countries with less poverty and more social support. This contradicts other sources [27,28,29], It would therefore seem that socioeconomic factors are more predictive of pain than specific occupations. However, the literature is conflicting as to whether higher or lower incomes are a risk factor for chronic pain.

\section{Limitations}

The difficulty of conducting a study of this kind has become apparent as the study progressed, due to both the paucity of data available from previous works and inconsistency in the definition of terms.

The data itself contained multiple errors and were affected by inconsistent recording, such as entries not being within the specified range or symbols being used to replace coded data, as well as missing fields. The fact that 512 entries were excluded weakened the strength of the study. The data collection process itself may also induce error as it relies on student osteopaths correctly recording data and this data then being correctly input into the electronic system, this may introduce an element of subjectivity and bias, both from students and patient reports. Furthermore, some data has component where multiple criteria may apply, which makes definitive analysis more difficult. An example of this is when defining the site of pain, such as mid back or upper back, where no clear anatomical boundary is set.

Data was grouped to increase the power of testing to statistically significant levels this may have impacted upon the results for age and ethnicity in particular as substantial differences may exist within these sub-populations, particularly with the wide range within the "pediatric and geriatric categories", with regards to the ethnicity data, the categories recorded are limited and there is no category for mixed race, although it is not known if this would affect the outcome of results. Nationality was not assessed, and it is uncertain if this would have an impact upon results.

It is acknowledged that multiple other factors influence patient presentation, these were impossible to adequately control or adjust for. As data is reduced to specific subgroups or compared with multiple variables the number of participants involved drops below the threshold needed to draw conclusions relevant to the larger population and is often below statistical significance.

Generalisability 
The design of this study as an observational study is only able to show correlation and not causation, although this study is a detailed profile of this patient profile. It contained more patient data than most previous studies and compared demographic and symptom data, highlighting possible links which had not been previously investigated. This study may be helpful as a comparison to similar works in other institutions or as a baseline comparison for future works to asses changes in the patient population at this OEI. This study adds to and updates the literature regarding day to day osteopathic practice.

\section{Conclusions}

This study is a detailed profile of the patient profile of the LSO clinic and may help to identify trends in the day to day practice of Osteopaths. Differences were found in patient presentation based on factors such as gender, age and ethnicity. This study has highlighted the need for further investigation into several areas, as well as exposing potential barriers to conducting meaningful research in this field. It is clear that there is a need for more rigorous, well-constructed studies in the fields of osteopathy and the epidemiology of musculoskeletal pain, with large numbers of patients to ensure that sample sizes are sufficiently large. It may be of benefit to identify groups at more risk of chronic pain.

\section{Declarations}

Ethical Approval and Consent to participate

Ethical Approval was granted by Anglia Ruskin Faculty of medicine and health sciences ethics committee and written consent to use anonymised data for research and publication was gained prospectively from all patients included. This retrospective study analysed pre-existing data, with no human contact.

Consent for publication

Anonymised data were accessed for this publication, prospective written informed consent was given for data collection, storage and analysis for the purpose of research and publication. No individuals or organisations are identified in this manuscript nor was it possible for the author to identify any individuals from the anonymised retrospective data set.

Availability of supporting data

Supporting data is available from the author on request.

Competing interests

The author has no competinginterests.

Funding

The author received no funding as this project formed the basis of a Masters thesis.

Authors' contributions

Andrew MacMillan is the sole author.

Acknowledgements

The author thanks the patients, staff and students of the institution for their time in assisting with research.

\section{References}

Page $10 / 12$ 
[1] England N. NHS England » Musculoskeletal [Internet]. England.nhs.uk. 2020 [cited 1 January 2020]. Available from: https://www.england.nhs.uk/ourwork/Itc-op-eolc/ltc-eolc/our-work-on-long-term-conditions/si-areas/musculoskeletal/

[2] Jordan JL, Holden MA, Mason EE, Foster NE. Interventions to improve adherence to exercise for chronic musculoskeletal pain in adults. Cochrane Database of Systematic Reviews. 2010(1). [Accessed 13 March 2017].

[3] Field JR, Newell D. Clinical outcomes in a large cohort of musculoskeletal patients undergoing chiropractic care in the United Kingdom: a comparison of self-and National Health Service-referred routes. Journal of manipulative and physiological therapeutics. 2016 Jan 1;39(1):54-62.

[4] Becker A, Held H, Redaelli M, Strauch K, Chenot JF, Leonhardt C, Keller S, Baum E, Pfingsten M, Hildebrandt J, Basler HD. Low back pain in primary care: costs of care and prediction of future health care utilization. Spine. 2010 Aug 15;35(18):1714-20.

[5] Maher C, Underwood M, Buchbinder R. Non-specific low back pain. The Lancet. 2017 Feb 18;389(10070):736-47.

[6] about osteopathy [Internet]. GOSC About osteopathy. 2017 [cited 22 February 2017]. Available from: http://www.osteopathy.org.uk/visiting-an-osteopath/about-osteopathy/>

[7] NHS England » The 14 allied health professions [Internet]. England.nhs.uk. 2020 [cited 1 January 2020]. Available from: https://www.england.nhs.uk/ahp/role/\#osteo

[8] NHS, 2015, Osteopathy [Internet]. nhs.uk. 2017 [cited 4 March 2017]. Available from: http://www.nhs.uk/conditions/osteopathy/pages/introduction.aspx

[9] Rushton AB, Fawkes CA, Carnes D, Moore AP. A modified Delphi consensus study to identify UK osteopathic profession research priorities. Manual therapy. 2014 Oct 1;19(5):445-52..

[10] Fawkes CA, Leach CM, Mathias S, Moore AP. A profile of osteopathic care in private practices in the United Kingdom: a national pilot using standardised data collection. Manual Therapy. 2014 Apr 1;19(2):125-30.

[11] Hinkley HJ, Drysdale IP. Audit of 1,000 patients attending the clinic of the British College of Naturopathy and Osteopathy (BCNO). British Osteopathic Journal. 1995:17-22.

[12]Mcllwraith B. A survey of 1200 osteopathic patients in the United Kingdom. Journal of Osteopathic Medicine. 2003 Apr 1;6(1):7-12. [13] Pringle, M. and Tyreman, S. 1993. Study of 500 patients attending an osteopathic practice. British Journal of General Practice, 43, pp.15-8.

[14] Burton AK. Back pain in osteopathic practice. Rheumatology. 1981 Nov 1;20(4):239-46.

[15] Schönbrodt FD, Perugini M. At what sample size do correlations stabilize?. Journal of Research in Personality. 2013 Oct 1;47(5):609-12.

[16] Bonett DG. Sample size requirements for estimating intraclass correlations with desired precision. Statistics in medicine. 2002 May 15;21(9):1331-5.

[17] Bailey JF, Sparrey CJ, Been E, Kramer PA. Morphological and postural sexual dimorphism of the lumbar spine facilitates greater lordosis in females. Journal of anatomy. 2016 Jul;229(1):82-91.

[18] Ernst E. Prevalence of use of complementary/alternative medicine: a systematic review. Bulletin of the world health organization. 2000;78:258-66. 
[19] London School of Osteopathy | Osteopathy Clinic | Bethnal Green [Internet]. LSO. 2017 [cited 1 January 2020]. Available from: http://lso.ac.uk/?page_id=32>

[20] Wilkinson J, Thomas KJ, Freeman JV, McKenna B. Day-to-day practice of osteopaths using osteopathy in the cranial field, who are affiliated with the Sutherland Cranial College of Osteopathy (SCCO): A national survey by means of a standardised data collection tool. International Journal of Osteopathic Medicine. 2015 Mar 1;18(1):13-21.

[21] Gersing AS, Link TM. Imaging of osteoarthritis in geriatric patients. Current radiology reports. 2016 Jan 1;4(1):4.

[22] Anderson AS, Loeser RF. Why is osteoarthritis an age-related disease?. Best practice \& research Clinical rheumatology. 2010 Feb 1;24(1):15-26.

[23] Giustino V. Chronic pain in the elderly: the case for new therapeutic strategies. Pain Physician. 2015 Sep;18(E863):E863-76.

[24] Neogi T. SP0067 Sensitization and Pain in OA.

[25] McBeth J, Lacey RJ, Wilkie R. Predictors of new-onset widespread pain in older adults: results from a population-based prospective cohort study in the UK. Arthritis \& Rheumatology. 2014 Mar;66(3):757-67.

[26] Farioli A, Mattioli S, Quaglieri A, Curti S, Violante FS, Coggon D. Musculoskeletal pain in Europe: role of personal, occupational and social risk factors. Scandinavian journal of work, environment \& health. 2014 Jan;40(1):36.

[27] Boyd E, Quiton R, Leibel D, Taylor A, Evans M, Waldstein S, Zonderman A. (241) Pain and poverty: a study of the intersectionality of demographic and socioeconomic factors on pain interference. The Journal of Pain. 2016 Apr 1;17(4):S35-6.

[28] Van Hecke O, Torrance N, Smith BH. Chronic pain epidemiology and its clinical relevance. British journal of anaesthesia. $2013 \mathrm{Jul}$ 1;111(1):13-8.

[29] Riskowski JL. Associations of socioeconomic position and pain prevalence in the United States: findings from the National Health and Nutrition Examination Survey. Pain Medicine. 2014 Sep 1;15(9):1508-21.

\section{Figures}

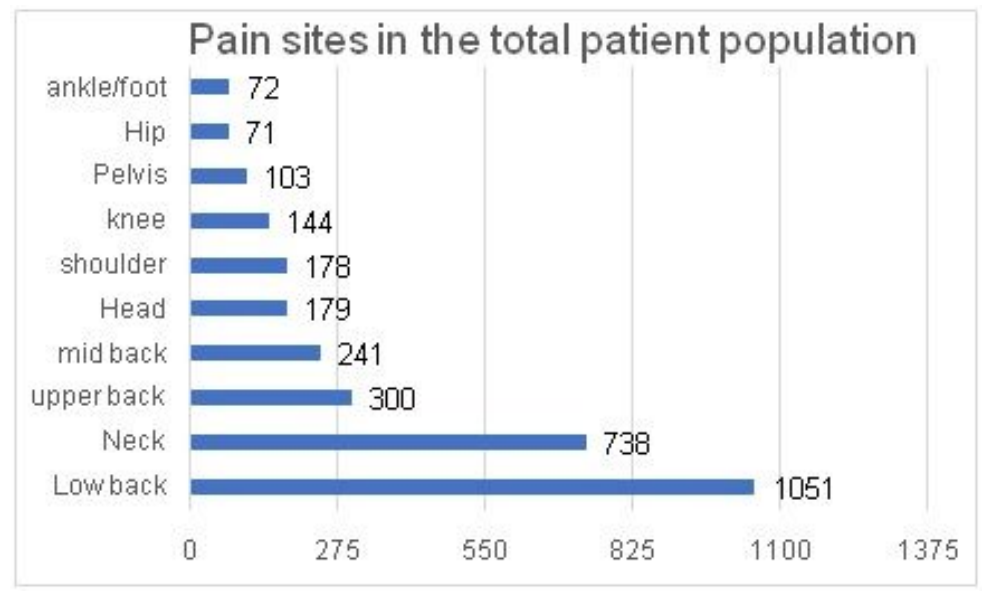

\section{Figure 1}

The 10 Most Common Sites of Pain 